\title{
Order Picking Systems: A Queue Model for Dimensioning the Storage Capacity, the Crew of Pickers, and the AGV Fleet
}

\author{
Francesco Lolli (D), ${ }^{1,2}$ Francesco Lodi $\left(\mathbb{D},{ }^{1}\right.$ Claudio Giberti $\left(\mathbb{D},{ }^{1}\right.$ Antonio Maria Coruzzolo (iD), \\ and Samuele Marinello (iD $^{2}$ \\ ${ }^{1}$ Department of Sciences and Methods for Engineering, University of Modena and Reggio Emilia, \\ Via Amendola 2, Padiglione Morselli, 42122 Reggio Emilia, Italy \\ ${ }^{2}$ EnઐTech Interdipartimental Center of the University of Modena and Reggio Emilia, Via Amendola 2, Padiglione Morselli, \\ 42122 Reggio Emilia, Italy
}

Correspondence should be addressed to Francesco Lolli; francesco.lolli@unimore.it

Received 6 September 2021; Accepted 19 January 2022; Published 24 February 2022

Academic Editor: Muhammet Gul

Copyright ( $\odot 2022$ Francesco Lolli et al. This is an open access article distributed under the Creative Commons Attribution License, which permits unrestricted use, distribution, and reproduction in any medium, provided the original work is properly cited.

Designing an order picking system can be very complex, as several interrelated control variables are involved. We address the sizing of the storage capacity of the picking bay, the crew of pickers, and the AGV fleet, which are the most important variables from a tactical viewpoint in a parts-to-pickers system. Although order picking is a widely explored topic in the literature, no analytical model that can simultaneously deal with these variables is currently available. To bridge this gap, we introduce a queue model for Markovian processes, which enables us to jointly optimise the aforementioned control variables. A discrete-event simulation is then used to validate our model, and we then test our proposal with real data under different operative scenarios, with the aim of assessing the usefulness of the proposal in real settings.

\section{Introduction}

Order picking is the retrieval of items in a warehouse to fulfil customer orders and is essential in end-product warehouses for guaranteeing high service levels to customers while aiming to reduce both operational and equipment costs. If automated guided vehicles (AGVs) operate from/to the order picking area, high equipment costs can be incurred, and operations can become very capital-intense [1].

Many authors have investigated this research area from various viewpoints because designing and controlling the order picking systems involves multiple objectives, which in turn lead to interrelated decisions. The time horizon is the most important consideration when categorising the main problems arising from designing and controlling order picking systems, and thus, strategic, tactical, and operational levels have been identified [2, 3]. At the strategic level, decisions mainly concern the layout design, the selection of the equipment for the material handling, and the corresponding level of automation. Refer to Rouwenhorst et al.
[2] and Davarzani and Norrman [4] for reviews of strategic decisions. These decisions clearly affect the performance of the order picking system but cannot be changed in the medium-short term and thus represent a constraint for the successive stages in an interrelated hierarchical framework [2].

Tactical decisions typically have an effect in the medium term and refer to the dimensioning of the resources, such as the storage capacity and the dimensioning of the picking zone [5]. Operational decisions usually affect daily operations such as batching, job assignment, and routing problems. Refer to Van den Berg [6] and Gu, Goetschalckx, and McGinnis [7] who focus on tactical and operational planning. A specific stream of research is devoted to combining these two levels and is reviewed in detail by van Gils et al. [5].

We focus on the tactical level, where the problem of dimensioning an order picking area involves more control variables, from the size of the forklift (or AGV) fleet to the number of pickers operating within the area. The pickers receive and separate the pallets coming from the warehouse 
according to the sequence and composition of the customer orders. In real settings, the storage capacity of the order picking area is generally upper bounded, so that the number of pallets that can be accepted within the dedicated area is limited. Thus, establishing the capacity of the order picking area, the number of pickers, and the number of forklifts (or $\mathrm{AGVs}$ ) is a complex issue due the interdependency of these control variables. Our work is innovative; as to the best of our knowledge, no other studies have addressed simultaneously designing the identified variables.

Methodologically, we use analytical modelling based on the queue theory combined with a stochastic and discreteevent simulation to numerically validate the model. Stochastic simulation is often used as a standalone approach for design purposes when the stochastic processes are modelled analytically [8] or assumed a priori; whereas, in the current work, the expected values of the relevant parameters are obtained numerically for a Markovian process, and thus, the simulation is used solely to validate the model.

The study is structured as follows. We first review the research background to frame our contribution in terms of the literature (Section 2) and our notation and assumptions (Section 3) and then propose a Markov model to simultaneously consider the control variables, with the aim of dimensioning the storage capacity of the picking area, the crew of pickers, and the AGV fleet (Section 4). This mathematical model is then validated by means of a discrete-event simulation approach (Section 5) and tested on real data (Section 6). Finally, Section 7 concludes and provides suggestions for further research.

\section{Literature Review}

The order picking process is the costliest activity in a warehouse and contributes to 55\% of the total operating costs [1], and according to KearneY [9], warehousing contributes to about $20 \%$ of surveyed companies' logistic costs.

Various types of order picking systems can be identified, and de Koster, Le-Duc, and Roodbergen [10] proposed a clear classification by subdividing the various systems into a hierarchy of levels. The first level distinguishes the order picking systems according to whether machines or humans are involved. Pick-and-place robots are generally used for automated picking systems. For human-based systems, the authors distinguish pickers-to-parts systems, parts-topickers systems, or put systems. In pickers-to-parts systems, the pickers walk or drive along the aisles to the pick items, while in parts-to-pickers systems, automated storage and retrieval systems (AS/RS) are typically combined with an AGV fleet to retrieve one or more unit loads, such as pallets or bins, and bring them to the pick positions. The order picker then takes the required number of pieces, and the remaining load is stored again if not empty [10]. In put systems, the items must be retrieved, both in parts-to-pickers and in pickers-to-parts systems, and the unit load is offered to a picker that distributes the prepicked items across the orders [11]. Dallari, Marchet, and Melacini [12] provided a more recent classification of order picking systems based on that of De Koster, Le-Duc, and Roodbergen [10], which involves four characteristics: who picks the items, who is involved in the picking area, the use of conveyors to connect picking areas, and the picking policy.

As stated, we focus on decisions at the tactical level, with the aim of jointly designing the storage capacity of the picking area, the crew of pickers, and the AGV fleet in a parts-to-pickers system, where the nonempty pallets are stored again after the picking operations end. Thus, we summarise in sequence the most relevant contributions to this research stream.

One of the first works on the design of picking systems was by Matson and White [13], who focus on equipment selection, warehouse layout, and the storage alternatives in automated picking systems. However, they do not provide any method for quantifying the aforementioned control variables.

Yoon and Sharp [14] proposed a structured approach for the analysis and design of order picking systems based on a literature review and interviews with experts in the field. The authors consider the interdependency between functional areas in an iterative top-down decomposition and bottomup modification [12], including the sizing of the picking area based on the deterministic flow of products. However, Rosenblatt and Roll [15] suggested that dynamic factors should be considered, such as the number of items, the average daily demand, the variation of daily demand, and the reorder level, but they do not address the issue we focus on.

Dallari, Marchet, and Melancini [12] extend the work of Yoon by including the choice of the most suitable order picking system at the selection stage, based on the number of items and the number of retrieval operations. Their study is based on data collected from 68 warehouses in Italy, but again, the joint design of the storage capacity of the picking area, the crew of pickers and the AGV fleet, is not addressed. Another relevant work is the survey of warehousing control and planning conducted by Van Der Berg who includes a review of order picking system designs, but only from the perspective of storage assignment.

De Koster, Le-Duc, and Roodbergen [10] provided an extensive review of order picking design and control and focus on studies that address the main problems arising in pickers-to-parts systems and highlight their interactions under a hierarchical decision framework consisting of layout, storage assignment, zoning, batching, and routing. They identify two main problems in layout design, i.e., facility location and internal layout, and focus on the latter. They refer to the model of Heragu et al. [16] for the sizing of the various areas, accounting for a deterministic demand rate and assigning items to functional areas (i.e., cross docking, forward, and reserve). However, they do not address the joint problem we intend to solve.

In a more recent study, Van Gils et al. [5] reviewed and classified studies considering the efficient design of order picking systems by combining planning problems. In their review, they focus on the interactions between the following tactical and operational problems: zone location and assignment, storage location assignment, workforce level and allocation, job assignment, batching, zone picking, routing, 
and order consolidation. Although they do not consider the combination of storage capacity and pickers' crew sizing, they note that the interaction between zoning at a tactical level and other planning problems should be investigated and that the first issue in zoning is the sizing of the storage capacity of the picking areas. This supports our suggestion that jointly sizing the crew of pickers and the AGVs fleet is necessary when evaluating the storage capacity of the order picking area. More recently, Jaghbeer, Hanson, and Johansson [17] provided an extensive review of the links between design and performance of order picking systems, with a particular focus on parts-to-pickers systems. Again, no joint sizing approach is identified in any previous work.

In our review of the literature on the design of order picking systems, we also find that few studies in the field of AGV fleet sizing concurrently address our problem. Le-Anh and De Koster [18] provided a comprehensive review.

The sizing of the AGV fleet is relevant as it can significantly influence the performance of the system [19]. Thus, many models are introduced in the literature and can be divided into four groups of approaches: simulation; analytical, including straightforward computations of the average performance of the AGV fleet; deterministic operations research; and stochastic operations research, including queuing, queuing networks, and closed queuing network models [20].

Currently, simulation approaches are mainly used to validate the analytical models, with some exceptions in which a simulation is used as a standalone designing approach (e.g., [21-23]).

Analytical (e.g., [24-27]) and deterministic operations research approaches (e.g., [28-30]), which are based on the common assumption that both the interarrival time between material requests and the AGV speed are given without uncertainty [20].

Stochastic operations research approaches include queuing models based on the steady-state behaviour of the system, as introduced by Yoda [31], Wysk et al. [32], and Talbot [33].

Hybrid models incorporating more than one approach have also been developed, such as the linear programming model based on closed queuing networks proposed by Choobineh, Asef-Vaziri, and Huang [20].

Thus, few studies propose designs of AGV fleets that aim to concurrently solve our problem, which further suggests our study is novel in this respect.

\section{Operative Environment and Assumptions}

The notation used throughout the article is given in Table 1.

A warehouse of finished products served by a fleet of AGVs of a finite number $U$ that conduct parallel missions is considered. We focus on the picking bay, which is the interface between the pickers and AGVs.

The interarrival times of AGVs to the picking bay are assumed as i.i.d. and are distributed according to an exponential probability distribution function with the ratio $\lambda$, i.e., $\operatorname{Exp}(\lambda)$. The pallets rather than AGVs determine $s$ pickers serving the picking bay. Indeed, AGVs are disconnected from the pallets, but the number and types of pallets into the system, together with the size $k$ of the picking bay (blocking queue), determine the use factor of the pickers and the number of AGVs potentially waiting in a busy status in the system. The pickers serve the pallets with times distributed according to an exponential probability distribution function with the ratio $\mu$, i.e., $\operatorname{Exp}(\mu)$. Thus, both the arrival and the service of the pallets are Markovian processes generating a queue that influences the performance of the overall warehouse system. Hence, the proposed system is indexable as $M / M / s / k / U$ according to Kendall's notation, where the tail discipline is assumed to be FIFO.

The system distinguishes between two types of pallets:

(i) Pallet_std: these are not empty once they are served and require a combined round-trip cycle; they can occupy the picker, a place in the system, and an AGV for the return trip.

(ii) Pallet_end: these are empty once they are served and occupy the picker and a place in the system, but the $\mathrm{AGV}$ is free to perform other missions after they are placed in the picking bay.

Figure 1 shows an example of the "Pallet_std" type: after picking, the nonempty pallet must be returned to the warehouse and thus requires an AGV. The AGV carrying the pallet in the warehouse must be unloaded.

Figure 2 shows an example of a "Pallet_end" type: the empty pallet leaves the system after the picking service without the need for an AGV and frees a place in the picking bay "autonomously."

We also assume that $\pi$ indicates the probability that a pallet arriving to the picking bay can be of the Pallet_end type.

Figure 3 shows a picking bay scheme: the pallets in the bay are denoted by rhombuses ("Pallet_std" to be brought back to the warehouse once they have been served) and triangles ("Pallet_end" to be emptied after the service); the black pallets are Pallet_std that have already been served and are waiting to be returned to the warehouse (as shown, once the pallet has been served, it no longer falls under the system state count $i$ ).

The AGV is not tied to a pallet, and after placing the pallet in the picking bay, it can climb on a second Pallet_std already served by carrying out the normal combined roundtrip mission without waiting for the service to be performed on the first pallet. However, to exchange the pallet, a free place is needed in the picking bay, so that the AGV can free itself from the input pallet and load the output pallet to return to the warehouse.

The AGV cannot bring new pallets to the picking bay when there are no vacant positions in the system ("vacant positions" are those not assigned either to physically present pallets or to other pallets that are about to arrive) and must wait in the queue in the busy state. This situation is not generated by the "Pallet_end" in the system, as they do not need to be moved by an AGV to free the place. Thus, the "Pallet_end" means the AGV does not need to wait in the 
TABLE 1: The adopted notation.

\begin{tabular}{|c|c|}
\hline$\lambda$ & Expected number of arrivals in a unit of time in the system for each AGV. \\
\hline$\lambda_{i}$ & Expected number of arrivals in a unit of time when the system is in the state $i$ \\
\hline $\bar{\lambda}$ & System throughput. \\
\hline$\mu$ & Expected number of pallets served in a unit of time by a single picker \\
\hline$\mu_{i}$ & Expected number of pallets served per unit of time whe \\
\hline$\pi i$ & $\begin{array}{c}\text { Probability that a pallet is of type Pallet_end. Number of pallets that are in picking bay plus the number of those waiting in } \\
\text { prequeue, that is the state of the system }\end{array}$ \\
\hline$p_{i}(t)$ & Probability that the syste \\
\hline$\Delta t$ & Probability that $\mathrm{t}$ \\
\hline$p_{i}$ & Probability that the system is in the state $i$ in the equilibrium (i.e. stationa \\
\hline$\rho$ & Traffic intensity of the system and use factor of the pickers \\
\hline$U$ & Size of \\
\hline$k$ & Storage $c$ \\
\hline$s$ & Nun \\
\hline$N p$ & Expect \\
\hline & xpected number of pallets in the system que \\
\hline$N^{q} \mathrm{C}$ & Expected \\
\hline Tpallet & n the system \\
\hline$T^{q}$ pallet & Expected time of a pallet in the system \\
\hline$T_{a g v}^{q^{2}}$ & Expected \\
\hline$n p b_{i}$ & $\begin{array}{l}\text { Maximum number of busy AGVs at the picking bay when the system is in state } i \text {, which coincides with the maximum number of } \\
\text { AGVs not really busy due to the presence of Pallet_end pallets in the picking bay }\end{array}$ \\
\hline$n b_{i}$ & $\begin{array}{c}\text { Expected number of busy AGVs at the picking bay when the system is in state } i \text {. The number of free AGVs when the system is in } \\
\text { state } i \text { is therefore }\left(U-n b_{i}\right)\end{array}$ \\
\hline$\Delta a g v_{i}$ & Expected difference between $n p b_{i}$ and $n b_{i}$ \\
\hline
\end{tabular}

In this study, all the time UoM are in seconds.
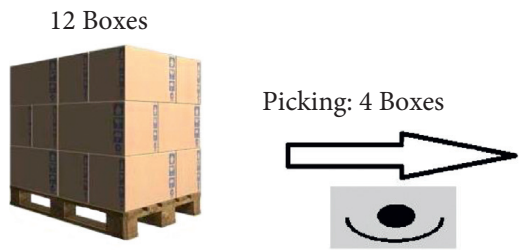

8 Boxes Left

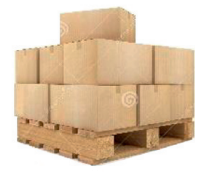

Figure 1: Example of "Pallet_std" type. The pallet with 8 packs is returned to the warehouse.
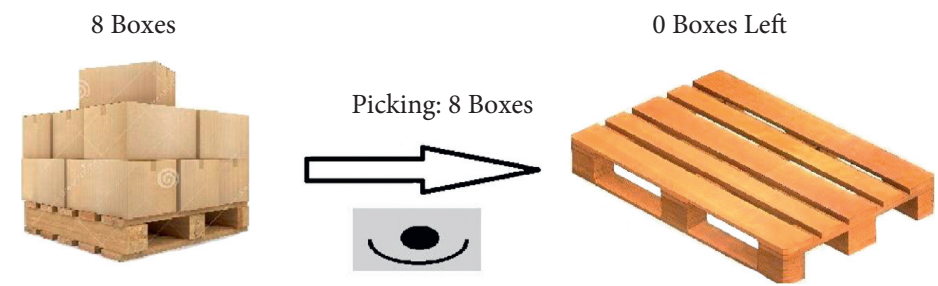

Figure 2: Example of "Pallet_end" type. After the service the pallet is empty, the pallet leaves the system autonomously.

queue in the busy state due to the lack of vacant positions in the picking bay. The marginal probabilities $p_{i>k}$, which are the probabilities that at steady state, there are $i$ pallets in the system with $i>k$, are then not necessarily zero, and on some occasions, the loaded AGV can wait in the busy state in a "prequeue" zone until a place in the picking bay occupied by a "Pallet_end" is freed autonomously.

Figure 4 shows the system involving the picking bay area and the prequeue zone. We can then define the status $i$ of the system, which is the variable representing the number of pallets of all types not yet served by the pickers that are located in the picking bay (placed in the pallet areas) and in the prequeue zone (loaded on the AGVs). This can assume values between 0 and $U+k$, inclusive, with the probability $p_{i}$ shown later.

In Figure 4, two "Pallet_end" (triangles) are within the picking bay and two AGVs loaded are waiting in the busy state in the prequeue zone, and thus, $i>k$.

For our measures, the system is assumed to have achieved a regime condition (steady state or equilibrium state), and thus, $p_{i}(t)$ denotes the probability that the system is in state $i$ at time $t$, and $p_{i}=\lim p_{i}(t)$ denotes the probability of the same state $i$ when the equilibrium is reached, regardless of the initial conditions. 


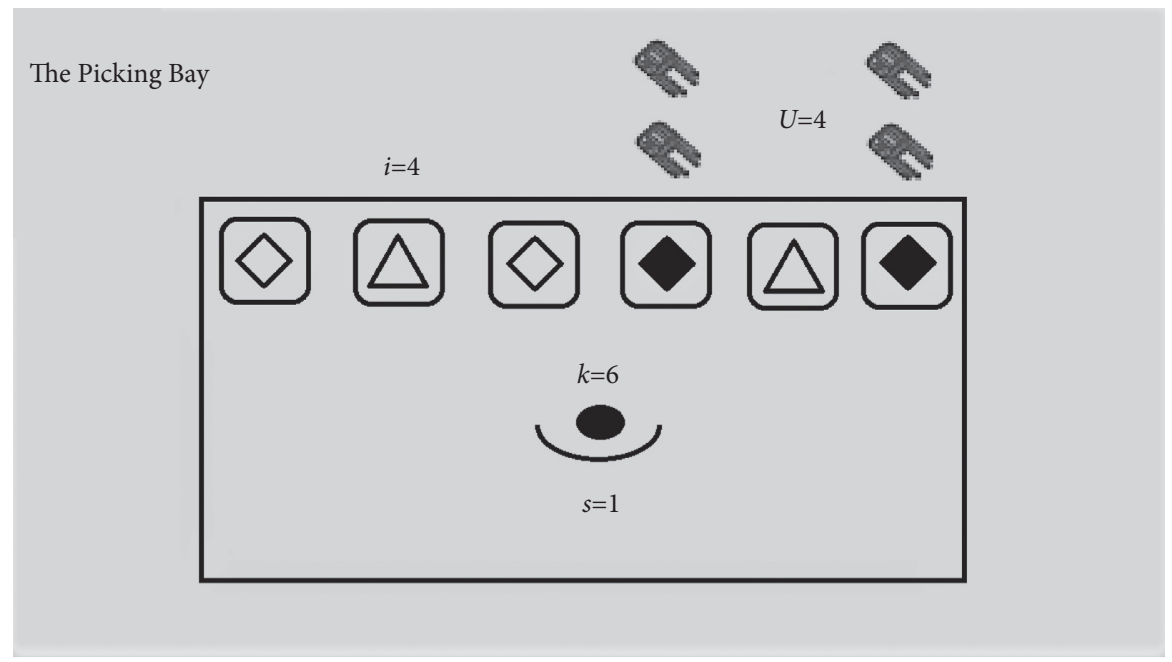

FIGURE 3: Scheme of the picking bay.

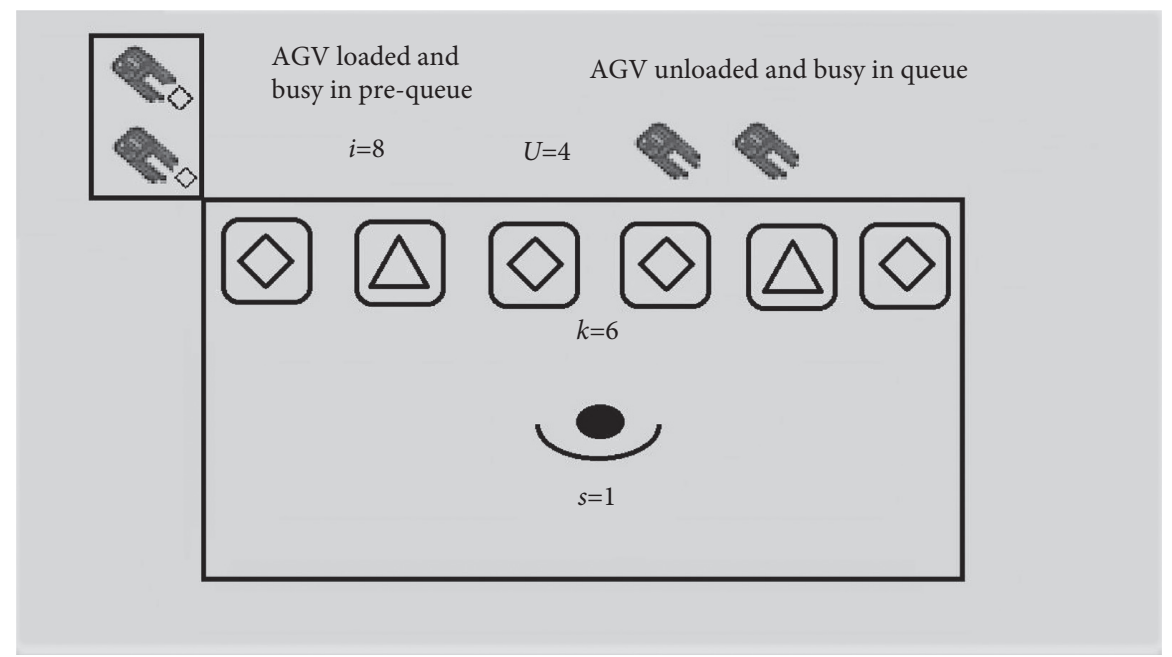

FIGURE 4: Scheme of the picking system (the picking bay with the prequeue zone).

We also assume the following:

(1) Congestion only occurs at the picking bay, and we do not consider it in the warehouse.

(2) An average AGV speed

(3) The general number of arrivals in the time unit is a Poisson variable with parameter $\lambda_{i}=\left(U-n b_{i}\right) \cdot \lambda$, as a function of the state $i$ of the system. The rate of arrivals strictly depends on the number of free AGVs in the system, which in turn depends both on the number of pallets $i$ and on the type of pallets in the system.

(4) $p_{i, m}(\Delta t)$ indicates the probability that the system switches from state $i$ to state $m$ in the time interval $\Delta t$, and thus, the following equations apply:

$$
\left\{\begin{array}{c}
p_{i, i+1}(\Delta t)=\lambda_{i} \cdot \Delta t+o(\Delta t) \text { with } i \geq 0 \\
p_{i, i-1}(\Delta t)=\mu_{i} \cdot \Delta t+o(\Delta t) \text { with } i \geq 1 \\
p_{i, m}(\Delta t)=o(\Delta t) \quad \text { with }|i-m| \geq 2
\end{array}\right\}
$$

where $o(\Delta t)$ tends to zero faster than $\Delta t$; thus, $o(\Delta t) / \Delta t \longrightarrow 00$.

These assumptions enable us to consider the system as a Markov chain, that is, the processes of birth and death depend only on the state in which the system is in and not on its history (i.e., a memoryless system). In addition, the PASTA ("Poisson Arrivals See Times Average") property applies to queue systems with Poissonian arrivals: the probability that an item arriving in the system at time $t$ will find the system in state $i$ is equal to the probability that the 
system at time $t$ is in state $i$. Thus, the value of the $p_{i}$ becomes even more important.

In this system, the values of $p_{i}$ depend only on the parameters $\lambda_{i}$ and $\mu_{i}$, which in turn change according with the state $i$ of the system as follows:

$$
\begin{aligned}
& p_{i}=\frac{\prod_{k=0}^{i-1} \lambda_{k}}{\prod_{j=1}^{i} \mu_{j}} \cdot p_{0}, \\
& p_{0}=\frac{1}{1+\sum_{i=1}^{\infty}\left(\prod_{k=0}^{i-1} \lambda_{k} / \prod_{j=1}^{i} \mu_{j}\right)} .
\end{aligned}
$$

The parameters of interest for the system are as follows: $\bar{\lambda}=\sum_{i=0}^{\infty} \lambda_{i} \cdot p_{i}$ (average arrival rate of pallets in the stationary state) $\left[t^{-1}\right]$ $\lambda_{i}= \begin{cases}U \cdot \lambda & \text { with } 0 \leq i \leq k-U \\ \operatorname{MAX}\left(k-i+\Delta a g v_{i} ; 0\right) \cdot \lambda & \text { with } i>k-U\end{cases}$ $\rho=\bar{\lambda} / \mu \cdot s$ (traffic intensity of the system and the use factor of the pickers)

$N$ pallet $=\sum_{i=0}^{\infty} i \cdot p_{i}$ (average number of pallets in the system in the stationary state)

$N^{q}$ pallet $=\sum_{i=s+1}^{\infty}(i-s) \cdot p_{i}$ (average number of pallets waiting to be served in the stationary state)

$N^{q} a g v=\sum_{i=0}^{\infty} n b_{i} \cdot p_{i} \quad$ (average number of AGVs waiting in busy state in the system in the stationary state)

Tpallet $=N$ pallet $/ \bar{\lambda}$ (average time of a pallet in the system in the stationary state) $[t]$

$T^{q}$ pallet $=N^{q}$ pallet $/ \bar{\lambda}$ (average waiting time of a pallet to be served in the stationary state) $[t]$

$T_{a g v}^{q}=N^{q} a g v / \bar{\lambda}$ (average time of AGVs that are waiting in busy status in the system in the stationary state) $[t]$

Examining the system logics that determine $\lambda_{i}$ and $\mu_{i}$ is therefore sufficient to derive all of the above measures. We therefore reduced the complexity of the system to the determination of the mathematical functions that guide the $\lambda_{i}$ and $\mu_{i}$ courses.

Finally, a basic constraint is that the arrival rate of the system is lower than its service rate, which avoids an infinite queue at the regime condition, and thus, the traffic intensity of the system must be less than $100 \%$.

\section{Analytical Modelling}

After presenting the logic that regulates arrivals, we define the relationships among $k, U$, and $i$ to determine $\lambda_{i}$ in the system.

The variables $n b_{i}$ and $n p b_{i}$ indicate the expected number of busy AGVs when the system is in state $i$ and the maximum possible number of busy AGVs in state $i$ if all the pallets were "Pallet_std", respectively. Generally, $n b_{i} \leq n p b_{i}$ for all $i$, particularly if the "Pallet_end" type is not present at the picking bay, as then $n b_{i}=n p b_{i}$ for all $i$.

Three analysis contexts are identified:

(1) $0 \leq i \leq k-U$. In this case, regardless of the type of pallets, all of the AGVs are free to carry out any kind of mission, as $(k-i)$ pallet places remain free, and as $i \leq k-U$, it follows that the number of free and unassigned pallet places is greater than $U$, and thus, there are no busy AGVs.

$$
\begin{aligned}
n b_{i} & =n p b_{i}=0 \text { with } 0 \leq i \leq k-U, \\
\lambda_{i} & =\left(U-n b_{i}\right) \cdot \lambda=U \cdot \lambda \text { with } 0 \leq i \leq k-U .
\end{aligned}
$$

Equation (4) precisely describes the handling potential of the AGV fleet as a function of the number of free AGVs, i.e., $\left(U-n b_{i}\right)$, in a certain state $i$ of the system, which is the total number of AGV $U$ minus the expected number of busy AGVs.

(2) $k-U<i<k$. In this context, the number of AGVs that is free to travel in the warehouse depends on the type of pallets in the picking bay.

If the pallets are all of the "Pallet_std" type, then the number of busy AGVs will be

$$
n b_{i}=n p b_{i}=U-(k-i)=i-k+U .
$$

The arrival parameter will depend only on the system state $i$ :

$\lambda_{i}=\left(U-n b_{i}\right) \cdot \lambda=[U-(i-k+U)] \cdot \lambda=[k-i] \cdot \lambda$.

For example, if $k=6, U=4$ and $i=4$ (Figure 3), then

$$
\begin{aligned}
n b_{4} & =n p b_{4}=4-6+4=2, \\
\lambda_{4} & =[6-4] \cdot \lambda=2 \cdot \lambda .
\end{aligned}
$$

that is, there are only 2 free AGVs in the warehouse that can carry out missions to bring other pallets to the picking bay, as the other 2 are at the picking bay waiting for a pallet to be served to free a bay place. We can now consider the presence of "Pallet_end" type pallets (note that the Pallet_end frees the AGV once it is placed in the picking bay). Pallets can be of the "Pallet_end" type according to a probability ratio of $\pi$, so the simplest way to model this is to use the expected value of the binomial variable on the tests $i \cdot \pi$ :

$$
\lambda_{i}=[k-i+i \cdot \pi] \cdot \lambda \text {. }
$$

However, for a case in which $\pi=25 \%, i=5, U=4$, and $k=8$, there are 5 pallets in the system, and $\pi$ of the pallets is "Pallet_end" that free AGV, but the maximum number of AGVs that can be freed depends on the number of AGVs that should be occupied $\left(n p b_{i}\right)$; with $i=5$, the expected number of Pallet_end will be

$$
i \cdot \pi=5 \cdot 25 \%=1.25 \text {. }
$$

It would also be greater than the maximum possible number of busy AGVs in that state $\left(n p b_{5}=1,(6)\right)$. We now define the variable $\Delta a g v_{i}$, such that $n b_{i}=n p b_{i}-\Delta a g v_{i}$ : 


$$
\Delta a g v_{i}=\sum_{x=0}^{n p b_{i}-1} x \cdot f_{x, i}+n p b_{i} \cdot \sum_{j=n p b_{i}}^{i} f_{j, i} \text { if } k-U<i<k .
$$

Here, the binomial variable $f_{x, i}$ is used to evaluate the probability that $x$ pallets in the state of the system $i$ are of "Pallet_end" type and therefore do not occupy AGVs in the queue in a busy state, i.e.,

$$
f_{x, i}= \begin{cases}\left(\begin{array}{l}
i \\
x
\end{array}\right) \cdot \pi^{x} \cdot(1-\pi)^{\mathrm{i}-x}, & \text { with } x: 0,1, \ldots i, \\
0, & \text { with } x>i,\end{cases}
$$

with $\pi$ being the probability that a pallet arriving to the picking bay is of the Pallet_end type.

Equation (10) can be interpreted as the expected value of AGVs that are not actually busy among the $n p b_{i}$ as some Pallet_end type pallets are present in the picking bay.

Thus, $n b_{i}$ (5)and $\lambda_{i}$ (6)are updated as follows:

$$
\begin{aligned}
\lambda_{i} & =\left[k-i+\Delta a g v_{i}\right] \cdot \lambda \quad \text { with } k-U<i<k, \\
& n b_{i}=U-\left(k-i+\Delta a g v_{i}\right)=i-k+U-\Delta a g v_{i}, \\
& \text { with } k-U<i<k .
\end{aligned}
$$

(3) $i \geq k$, when $i$ is at least equal to $k$; all pallet places in the picking bay are occupied, and the maximum possible number of busy AGVs $\left(n p b_{i}\right)$ is always equal to $U$ :

$$
n p b_{i}=U, \quad \text { with } i \geq k,
$$

and the expected number of "Pallet_end" pallets can only be evaluated for those currently present in the picking bay (i.e., $k$ ). Thus, the pallets loaded on the busy AGVs waiting in the prequeue (Figure 4) should not be evaluated (note that the Pallet_end frees the AGV once it is placed in one of the $k$ places in the picking bay and not before). Then,

$$
\Delta a g v_{i}=\sum_{x=0}^{U-1} x \cdot f_{x, k}+U \cdot \sum_{j=U}^{i} f_{j, k}, \quad \text { if } i \geq k .
$$

As the arrival rate cannot become negative, $\lambda_{i}$ is obtained by updating (12) as follows:

$$
\lambda_{i}=\operatorname{MAX}\left[k-i+\Delta a g v_{i} ; 0\right] \cdot \lambda \text { with } i \geq k
$$

By calculating the following values of $n p b_{i}$,

$$
n p b_{i}= \begin{cases}0, & \text { if } 0 \leq i \leq k-U, \\ i-k+U, & \text { if } k-U<i<k \\ U, & \text { if } i \geq k\end{cases}
$$

and applying it to the generic formula for $\Delta a g v_{i}$ (10), it follows that

$\Delta a g v_{i}= \begin{cases}0, & \text { if } i \leq k-U, \\ \sum_{x=0}^{i-k+U-1} x \cdot f_{x, i}+(i-k+U) \cdot \sum_{j=i-k+U}^{i} f_{j, i}, & \text { if } k-U<i<k, \\ \sum_{x=0}^{U-1} x \cdot f_{x, k}+U \cdot \sum_{j=U}^{i} f_{j, k}, & \text { if } i \geq k,\end{cases}$

It should be noted that when $k=U$,

$$
\operatorname{agv}_{i}= \begin{cases}0, & \text { if } i=0, \\ \sum_{x=0}^{i-1} x \cdot f_{x, i}+(i) \cdot \sum_{j=i}^{i} f_{j, i}=\pi \cdot i, & \text { if } 0<i<k, \\ \sum_{x=0}^{U-1} x \cdot f_{x, k}+U \cdot \sum_{j=U}^{i} f_{j, k}=\pi \cdot k, & \text { if } i \geq k,\end{cases}
$$

The following are instead the values of $\lambda_{i}$ and $n b_{i}$ :

$$
\lambda_{i}= \begin{cases}U \cdot \lambda, & \text { with } 0 \leq i \leq k-U, \\ \operatorname{MAX}\left(k-i+\Delta a g v_{i} ; 0\right) \cdot \lambda, & \text { with } i>k-U,\end{cases}
$$

$n b_{i}= \begin{cases}0, & \text { with } 0 \leq i \leq k-U, \\ \operatorname{MIN}\left(i-k+U-\Delta a g v_{i} ; U\right), & \text { with } i>k-U,\end{cases}$

In terms of the service rate of the system $\mu_{i}$, the following relations can be achieved depending on the state of the system with $s \leq k$ :

$$
\mu_{i}= \begin{cases}i \cdot \mu, & \text { if } 1 \leq i<s, \\ s \cdot \mu, & \text { if } i \geq s .\end{cases}
$$

Equations (17), (18), (20), and (21) are derived based on the operating logic expressed in Section 3 and therefore are only valid for $k \geq U$. If $k$ is lower than $U$ and waiting in a prequeue is possible, the logic would completely change, resulting in a pure $M / M / s /$. / system where each AGV follows a pallet, waits in a prequeue with the pallet, and awaits the operator's service before embarking on a new mission.

Once $\lambda_{i}$ and $\mu_{i}$ are determined for each state of the system, we can calculate the marginal probabilities $p_{i}$ and consequently all the parameters of interest for the system (Section 3).

\section{Model Validation}

We use a discrete-event simulator $\left(\right.$ AnyLogic $\left.^{\circledR}\right)$ to validate the model, which is set with the same logic as that underlying the model (Section 3).

Tables 2-5 present the input parameters used $(\lambda, \mu, s, k, U)$ and the relative output variables from the model $\left(10^{\text {th }}\right.$ column $)$ and from the simulator $\left(11^{\text {th }}\right.$ column $)$ for the 15 tests conducted by varying the input parameters. 
TABLE 2: Comparison between model throughput $(\bar{\lambda})$ and simulator throughput $(\bar{\lambda} \operatorname{sim})$.

\begin{tabular}{lccccccccccc}
\hline Id & $\lambda$ & $\mu$ & $\mathbf{s}$ & $\mathbf{k}$ & $\mathbf{U}$ & \# miss $_{\text {fp }}$ & $\hat{\lambda} \operatorname{sim}$ & $\hat{\mu} \operatorname{sim}$ & $\bar{\lambda}$ & $\lambda$ sim & $\Delta(\%)$ \\
\hline 1 & 5 & 10 & 1 & 3 & 2 & 5000 & 5.00 & 9.99 & 7.50 & 7.47 & 0 \\
2 & 5 & 10 & 2 & 10 & 5 & 5000 & 5.01 & 9.99 & 19.39 & 19.35 & 0 \\
3 & 10 & 20 & 2 & 15 & 5 & 5000 & 10.10 & 19.46 & 39.72 & 38.74 & 2 \\
4 & 10 & 50 & 1 & 6 & 3 & 5000 & 10.04 & 50.62 & 29.30 & 29.47 & 1 \\
5 & 20 & 10 & 2 & 20 & 4 & 5000 & 19.70 & 10.00 & 20.00 & 19.99 & 0 \\
6 & 20 & 40 & 1 & 10 & 6 & 5000 & 19.95 & 40.56 & 40.00 & 40.56 \\
7 & 20 & 40 & 2 & 6 & 4 & 5000 & 0.20 & 39.93 & 65.73 & 65.65 & 0 \\
8 & 30 & 30 & 2 & 5 & 3 & 5000 & 30.17 & 29.63 & 56.13 & 55.31 & 1 \\
9 & 30 & 30 & 2 & 10 & 3 & 5000 & 29.85 & 30.42 & 59.70 & 60.53 & 1 \\
10 & 30 & 50 & 2 & 5 & 4 & 5000 & 30.42 & 49.54 & 84.10 & 84.05 \\
11 & 30 & 50 & 2 & 10 & 4 & 5000 & 30.56 & 49.79 & 96.69 & 96.69 & 0 \\
12 & 30 & 50 & 1 & 5 & 4 & 5000 & 29.76 & 49.42 & 49.42 & 48.80 \\
13 & 30 & 50 & 1 & 10 & 4 & 5000 & 30.19 & 49.49 & 50.00 & 49.44 \\
14 & 50 & 10 & 4 & 10 & 2 & 5000 & 50.02 & 9.99 & 39.99 & 39.89 \\
15 & 50 & 10 & 9 & 10 & 2 & 5000 & 48.77 & 10.01 & 79.72 & 78.83 \\
\hline
\end{tabular}

TABLE 3: Comparison of the utilization rate of the pickers between the model $(\rho)$ and the simulator ( $\rho$ sim).

\begin{tabular}{lccccccccccc}
\hline Id & $\lambda$ & $\mu$ & $\mathbf{s}$ & $\mathbf{k}$ & $\mathbf{U}$ & ${\text { \# } \text { miss }_{\text {fp }}}$ & $\hat{\lambda} \operatorname{sim}$ & $\widehat{\mu} \operatorname{sim}$ & $\rho$ & $\boldsymbol{\rho}$ sim & $\Delta(\%)$ \\
\hline 1 & 5 & 10 & 1 & 3 & 2 & 5000 & 5.00 & 9.99 & 0.75 & 0.75 & 0 \\
2 & 5 & 10 & 2 & 10 & 5 & 5000 & 5.01 & 9.99 & 0.97 & 0.97 & 0 \\
3 & 10 & 20 & 2 & 15 & 5 & 5000 & 10.10 & 19.46 & 0.99 & 0.99 & 0 \\
4 & 10 & 50 & 1 & 6 & 3 & 5000 & 10.04 & 50.62 & 0.59 & 0.58 & 1 \\
5 & 20 & 10 & 2 & 20 & 4 & 5000 & 19.70 & 10.00 & 1.00 & 1.00 & 0 \\
6 & 20 & 40 & 1 & 10 & 6 & 5000 & 19.95 & 40.56 & 1.00 & 1.00 & 0 \\
7 & 20 & 40 & 2 & 6 & 4 & 5000 & 0.20 & 39.93 & 0.82 & 0.82 \\
8 & 30 & 30 & 2 & 5 & 3 & 5000 & 30.17 & 29.63 & 0.94 & 0.93 \\
9 & 30 & 30 & 2 & 10 & 3 & 5000 & 29.85 & 30.42 & 1.00 & 1.00 \\
10 & 30 & 50 & 2 & 5 & 4 & 5000 & 30.42 & 49.54 & 0.84 & 0.85 \\
11 & 30 & 50 & 2 & 10 & 4 & 5000 & 30.56 & 49.79 & 0.97 & 0.97 & 1 \\
12 & 30 & 50 & 1 & 5 & 4 & 5000 & 29.76 & 49.42 & 0.99 & 0.99 & 0 \\
13 & 30 & 50 & 1 & 10 & 4 & 5000 & 30.19 & 49.49 & 1.00 & 1.00 \\
14 & 50 & 10 & 4 & 10 & 2 & 5000 & 50.02 & 9.99 & 1.00 & 1.00 & 0 \\
15 & 50 & 10 & 9 & 10 & 2 & 5000 & 48.77 & 10.01 & 0.89 & 0.88 \\
\hline
\end{tabular}

TABLE 4: Comparison between the actual queue time of the AGVs in the model $\left(\mathbf{T}_{\mathbf{a g v}}^{\mathbf{q}}\right)$ and in the simulator $\left(\mathrm{T}_{\mathbf{a g v}}^{\mathrm{q}}\right.$ sim).

\begin{tabular}{|c|c|c|c|c|c|c|c|c|c|c|c|}
\hline Id & $\lambda$ & $\mu$ & s & $\mathbf{k}$ & $\mathbf{U}$ & $\#$ miss $_{\mathrm{fp}}$ & $\widehat{\lambda} \operatorname{sim}$ & $\widehat{\mu} \operatorname{sim}$ & $\mathrm{T}_{\mathrm{agv}}^{\mathrm{q}}$ & $\mathrm{T}_{\mathrm{agv}}^{\mathrm{q}} \operatorname{sim}$ & $\Delta(\%)$ \\
\hline 1 & 5 & 10 & 1 & 3 & 2 & 5000 & 5.00 & 9.99 & 240.28 & 244.88 & 2 \\
\hline 2 & 5 & 10 & 2 & 10 & 5 & 5000 & 5.01 & 9.99 & 208.20 & 211.22 & 1 \\
\hline 3 & 10 & 20 & 2 & 15 & 5 & 5000 & 10.10 & 19.46 & 93.15 & 107.24 & 15 \\
\hline 4 & 10 & 50 & 1 & 6 & 3 & 5000 & 10.04 & 50.62 & 8.60 & 7.32 & 15 \\
\hline 5 & 20 & 10 & 2 & 20 & 4 & 5000 & 19.70 & 10.00 & 540.00 & 534.41 & 1 \\
\hline 6 & 20 & 40 & 1 & 10 & 6 & 5000 & 19.95 & 40.56 & 360.01 & 347.03 & 4 \\
\hline 7 & 20 & 40 & 2 & 6 & 4 & 5000 & 0.20 & 39.93 & 39.09 & 37.74 & 3 \\
\hline 8 & 30 & 30 & 2 & 5 & 3 & 5000 & 30.17 & 29.63 & 72.41 & 74.34 & 3 \\
\hline 9 & 30 & 30 & 2 & 10 & 3 & 5000 & 29.85 & 30.42 & 60.90 & 56.74 & 7 \\
\hline 10 & 30 & 50 & 2 & 5 & 4 & 5000 & 30.42 & 49.54 & 51.23 & 51.01 & 0 \\
\hline 11 & 30 & 50 & 2 & 10 & 4 & 5000 & 30.56 & 49.79 & 28.94 & 30.57 & 6 \\
\hline 12 & 30 & 50 & 1 & 5 & 4 & 5000 & 29.76 & 49.42 & 171.38 & 170.67 & 0 \\
\hline 13 & 30 & 50 & 1 & 10 & 4 & 5000 & 30.19 & 49.49 & 168.01 & 168.57 & 0 \\
\hline 14 & 50 & 10 & 4 & 10 & 2 & 5000 & 50.02 & 9.99 & 108.02 & 107.07 & 1 \\
\hline 15 & 50 & 10 & 9 & 10 & 2 & 5000 & 48.77 & 10.01 & 18.32 & 17.29 & 6 \\
\hline
\end{tabular}


TABLE 5: Comparison between the time in the queue and prequeue of pallets of each type in the model ( $\mathbf{T}^{\mathrm{q}}$ pallet) and in the simulator ( $\mathrm{T}^{\mathrm{q}}$ pallet sim).

\begin{tabular}{|c|c|c|c|c|c|c|c|c|c|c|c|}
\hline Id & $\lambda$ & $\mu$ & $\mathbf{s}$ & $\mathbf{k}$ & $\mathbf{U}$ & $\#$ miss $_{\mathrm{fp}}$ & $\widehat{\lambda} \operatorname{sim}$ & $\widehat{\mu} \operatorname{sim}$ & $\mathrm{T}^{\mathrm{q}}$ pallet & $\mathrm{T}^{\mathrm{q}}$ pallet sim & $\Delta(\%)$ \\
\hline 1 & 5 & 10 & 1 & 3 & 2 & 5000 & 5.00 & 9.99 & 392.34 & 394.30 & 1 \\
\hline 2 & 5 & 10 & 2 & 10 & 5 & 5000 & 5.01 & 9.99 & 936.41 & 944.19 & 1 \\
\hline 3 & 10 & 20 & 2 & 15 & 5 & 5000 & 10.10 & 19.46 & 945.97 & 991.64 & 5 \\
\hline 4 & 10 & 50 & 1 & 6 & 3 & 5000 & 10.04 & 50.62 & 84.99 & 77.48 & 9 \\
\hline 5 & 20 & 10 & 2 & 20 & 4 & 5000 & 19.70 & 10.00 & 3737.54 & 3702.81 & 1 \\
\hline 6 & 20 & 40 & 1 & 10 & 6 & 5000 & 19.95 & 40.56 & 852.46 & 834.68 & 2 \\
\hline 7 & 20 & 40 & 2 & 6 & 4 & 5000 & 0.20 & 39.93 & 69.79 & 70.41 & 1 \\
\hline 8 & 30 & 30 & 2 & 5 & 3 & 5000 & 30.17 & 29.63 & 124.80 & 133.62 & 7 \\
\hline 9 & 30 & 30 & 2 & 10 & 3 & 5000 & 29.85 & 30.42 & 439.39 & 423.48 & 4 \\
\hline 10 & 30 & 50 & 2 & 5 & 4 & 5000 & 30.42 & 49.54 & 46.17 & 48.95 & 6 \\
\hline 11 & 30 & 50 & 2 & 10 & 4 & 5000 & 30.56 & 49.79 & 195.35 & 203.33 & 4 \\
\hline 12 & 30 & 50 & 1 & 5 & 4 & 5000 & 29.76 & 49.42 & 249.31 & 250.77 & 1 \\
\hline 13 & 30 & 50 & 1 & 10 & 4 & 5000 & 30.19 & 49.49 & 695.30 & 697.15 & 0 \\
\hline 14 & 50 & 10 & 4 & 10 & 2 & 5000 & 50.02 & 9.99 & 616.05 & 608.67 & 1 \\
\hline 15 & 50 & 10 & 9 & 10 & 2 & 5000 & 48.77 & 10.01 & 31.86 & 30.54 & 4 \\
\hline
\end{tabular}

Note that for each simulation, a very high value of missions is used (5000, column "\#miss $f p$ " of each table) to mask the simulated system warm-up phase and compare the data at a steady state (collection periods). $\hat{\mu} \operatorname{sim}$ and $\widehat{\mu} \operatorname{sim}$ represent the average number of arrivals per unit of time for each AGV and of pallets served in a unit of time by a single picker for the actual simulation case, respectively. These can be used to justify any increases in the comparison $\Delta$.

The greatest difference is found in the evaluation of the variable $T_{a g v}^{q} \operatorname{sim}$ (Table 4), but this occurs because the number measured by the model is based on an inaccurate formula used in the simulator. Thus, we exclude this variable, and the highest deviation then occurs in the fourth case (Table $5,4^{\text {th }}$ row). Here, the deviation in terms of pallet queue time is because the growth of $\mu$ of the simulator (column $\hat{\mu} \mathrm{sim}$ ) in terms of the input parameter of the model (column $\mu$ ) causes a considerable reduction in picking time, which has even more of an effect as there is only one picker in the system. The same consideration has the opposite effect (the 7\% delta) for the eighth case (Table $5,8^{\text {th }}$ row), in which the parameter $\mu$ measured at the end of the simulation (column " $\hat{\mu} \operatorname{sim}$ ") is smaller than the input parameter used in the model (column " $\mu \prime \prime)$, so the variable $T^{q}$ pallet is less than the counterpart $T^{q}$ pallet sim of the simulator.

The results obtained in these tests confirm the accuracy of the $M / M / s / k / U$ model with the previous pallet type differentiation.

\section{Model Testing on Real Data}

In this section, we test the model on real data, from which we derived the requirements for sizing a fleet of AGVs for a finished product warehouse. The method used to obtain the input parameters of the service system is explained in Section 6.1, based on the knowledge that the AGVs within the warehouse conduct different types of missions. In Section 6.2, we then test and compare the various models of queues in terms of results and logic.
6.1. Data Collection. Figure 5 shows the storage area of the plant.

Four activities are conducted within the storage area: stock missions and entire pallet picking missions $\left(\right.$ \#miss $_{\text {ep }}=0.25$ - \#pick), along with fractional picking missions (\#miss $f p=0.75 \cdot$ \#pick) for both Pallet_std $\left((1-\pi) \cdot\right.$ miss $\left._{f p}\right)$ and Pallet_end $\left(\pi \cdot \#\right.$ miss $\left._{f p}\right)$.

The following tables provide the expected values of missions during the day in terms of number (Table 6), distance (Table 6), and velocity (Table 7).

The reference value for the number of missions covers $95 \%$ of the days in the year.

By applying the hypothesis of equal access probabilities, the basic distances for the various AGV shifts can be calculated (Table 7). Table 8 provides the characteristics of the AGV.

Using the data in Tables 7 and 8 , the expected times for the basic movements can be calculated (Table 9).

Note that by assuming the reference values that cover $95 \%$ of the output and input events, it follows that

$$
T w h 1=\frac{61.6 \cdot 462}{462+155}=46.1(\mathrm{sec}),
$$

We can then obtain the expected time of each mission by analysing the process:

(1) Stock mission: this is a round-trip cycle from the warehouse to the AGV I/O point (Figure 5, point A), with the assumption that the AGVs are only raised and lowered in masked time when the AGV is discharged; as the return journey to the warehouse is loaded, moving in the warehouse to the position required by the next mission should be added unless this is a stock mission (Twh1). Hence,

$$
\begin{aligned}
\text { Tstock } & =T x y 1 \cdot 2+T z+T \text { fio } \cdot 2+T w h 1 \\
& =162.9 s+T w h 1 .
\end{aligned}
$$

(2) Entire picking mission: these correspond to 25\% of the output missions and consist of the round-trip 


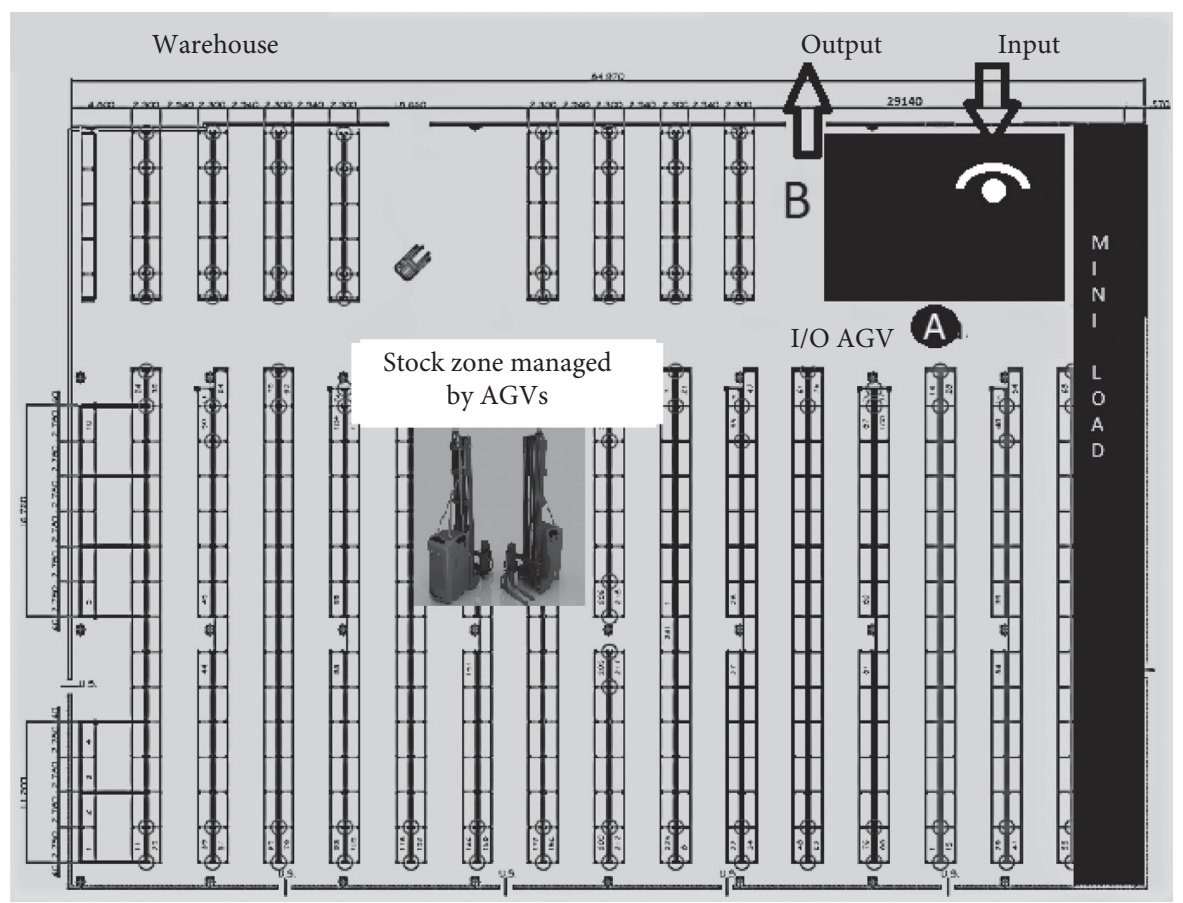

FIgURE 5: Conceptual layout of the warehouse.

TABLE 6: Values of pallet input trends.

\begin{tabular}{lcc}
\hline & \#stock (pallet/day) & \#pick (pallet/day) \\
\hline Average & 98 & 325 \\
Std dev & 41 & 73 \\
Max & 212 & 566 \\
$95 \%$ & 155 & 462 \\
\hline
\end{tabular}

$95 \%$ indicates the value that covers $95 \%$ of the analysed days.

TABLE 7: Basic average distances.

\begin{tabular}{lcc}
\hline Distances & Descriptions & Meters \\
\hline Dhor 1 & Average barycentric distance between the picking bay (Figure 5, point A) and the warehouse. & 61.2 \\
Dhor 2 & Average barycentric distance between the output point (Figure 5, point B) and the warehouse. & 77.7 \\
Dmag & Average travel distance between two compartments in the warehouse. About 2400 travel combinations are evaluated. & 61.6 \\
Hm & Average height of the compartment in the warehouse (base of the compartment). & 3.5 \\
\hline
\end{tabular}

TABle 8: The parameters of the AGV.

\begin{tabular}{lcc}
\hline Characteristic & Velocity $(\mathrm{m} / \mathrm{min})$ & Velocity $(\mathrm{m} / \mathrm{s})$ \\
\hline Vhormax & $80 \mathrm{~m} / \mathrm{min}$ & $1.33 \mathrm{~m} / \mathrm{s}$ \\
Vhor & $60 \mathrm{~m} / \mathrm{min}$ & $1 \mathrm{~m} / \mathrm{s}$ \\
Vvert & $20 \mathrm{~m} / \mathrm{min}$ & $0.33 \mathrm{~m} / \mathrm{s}$ \\
V forks I/O & $12 \mathrm{~m} / \mathrm{min}$ & $0.2 \mathrm{~m} / \mathrm{s}$ \\
\hline
\end{tabular}

Table 9: Basic times summary.

\begin{tabular}{|c|c|c|c|}
\hline Parameter & Description & Formula & $\begin{array}{l}\text { Time } \\
(\mathrm{sec})\end{array}$ \\
\hline Tfio & Fixed forks time (value measured on the field) & & 15 \\
\hline$T x y 1$ & $\begin{array}{c}\text { Average horizontal time from the I/O AGV to a compartment in the } \\
\text { warehouse }\end{array}$ & Dhor $1 /$ Vhor & 61.2 \\
\hline$T x y 2$ & Average horizontal time up to the output roller conveyor & Dhor2/Vhor & 77.7 \\
\hline Twh & Average intrawarehouse transfer time & Dmag/Vhor & 61.6 \\
\hline Twh 1 & 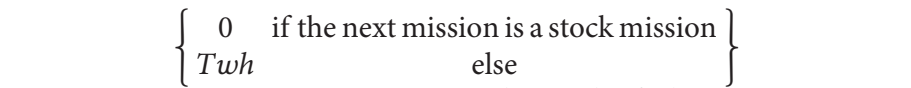 & Twh $\cdot \#$ pick $+0 \cdot \#$ stock/\#pick $+\#$ stock & \\
\hline$T z$ & Average time to raise/lower the forks & $\mathrm{Hm} / \mathrm{Vvert}$ & 10.5 \\
\hline
\end{tabular}


TABLe 10: Outputs of $\mathrm{M} / \mathrm{M} / \mathrm{s}$.

\begin{tabular}{ccccccccccc}
\hline Id & $\lambda$ & $\mu$ & $\mathrm{U}$ & $\mathrm{s}$ & $\lambda \cdot \mathrm{U}$ & $\rho$ & $N$ pallet & $T$ pallet & $\mathrm{N}^{\mathrm{q}}$ pallet & $\mathrm{T}^{\mathrm{q}}$ pallet \\
\hline 1 & 9.32 & 49.69 & 1 & 1 & 9.32 & 0.19 & 0.23 & 89.19 & 0.04 \\
2 & 9.32 & 49.69 & 2 & 1 & 18.65 & 0.38 & 0.60 & 115.98 & 0.23 \\
3 & 9.32 & 49.69 & 3 & 1 & 27.97 & 0.56 & 1.29 & 165.78 & 0.73 \\
4 & 9.32 & 49.69 & 4 & 1 & 37.30 & 0.75 & 3.01 & 290.51 & 2.26 \\
5 & 9.32 & 49.69 & 5 & 1 & 46.62 & 0.94 & 15.20 & 1173.39 & 14.26 \\
6 & 9.32 & 49.69 & 6 & 1 & 55.94 & 1.13 & $+\infty$ & $+\infty$ & 218.06 \\
& & & & & & & & & & $+\infty$ \\
\hline
\end{tabular}

cycle from the warehouse to the I/O roller conveyor (Figure 5, point B), with the assumption that $T z$ is only masked when the AGV is unloaded; as there is no loaded return trip to the warehouse, these do not need the addition of the horizontal transition time between two stock places. Thus,

Tep $=$ Txy2 $\cdot 2+T z+T$ fio $\cdot 2=195.9 s$.

(3) Fractional picking mission for Pallet_std: these correspond to $(1-\pi) \cdot$ \#miss $_{f p}$; by assuming that the AGV is already in the warehouse in front of the space required for the mission, the fractional picking cycle consists of the following:

I. Raising of forks in masked time.

II. $T$ fio to extract the pallet.

III. $T z$ for lowering forks in nonmasked time.

IV. Txy 1 to reach the picking bay.

V. $T$ fio to dispose of the pallet.

VI. $T$ fio to load another pallet already served by the picking bay.

VII. $T x y 1$ to return the last pallet from the picking bay to the warehouse compartment.

VIII. $T z$ not masked for raising forks.
IX. T fio to dispose of the served pallet.

$\mathrm{X}$. Lowering of forks in masked time.

$\mathrm{XI}$. Twh 1 to go to the warehouse position required by the next mission.

Thereby,

$$
\begin{aligned}
T f p_{\text {st } d} & =T \text { fio } \cdot 4+T z \cdot 2+T x y 1 \cdot 2+T w h 1 \\
& =203.4+T w h 1(\mathrm{sec}),
\end{aligned}
$$

(4) Finally, on average, $\pi \cdot \#$ miss $s_{p f}$ pallets are of type Pallet_end, and a combined cycle such as $T p f 1$ will not be necessary. The mission coincides with a stock mission, as simply by reversing the loaded travel phases with the empty phases, and therefore, the addition of the horizontal transition time Twh 1 between the warehouse compartments is not required:

$$
T f p_{\text {end }}=\text { Tstock }-T w h 1=162.9(\mathrm{sec}) .
$$

Given the times and the expected number of missions for each type (using the value for the number of missions, which covers $95 \%$ of the days in the year), we can easily derive the expected total time required for the execution of these missions:

Ttot $=$ Tstock $\cdot \#$ stock $+\left\{\left[(1-\pi) \cdot T f p_{-}\right.\right.$std $+\pi \cdot T f p_{-}$end $\left.] \cdot 75 \%+T e p \cdot 25 \%\right\} \cdot \#$ pick $=37.13$ (hours)

with $\pi$ measured on the field given by

$$
\pi=\frac{1}{3,8943}=0.2568
$$

Considering that the AGV only visits the picking bay in fractional picking missions, we can calculate $\lambda$ as follows:

$$
\lambda=\frac{\#_{\text {miss }}^{f p}}{\text { Ttot }}=\frac{462 \cdot 75 \%}{37,13 \text { hour }}=9.32\left(\frac{\text { miss }}{\text { hour } \cdot A G V}\right) .
$$

We also obtain from the field that

$$
\mu=49.69\left(\pi \frac{\text { missions }}{\text { hour } \cdot \text { picker }}\right) \text {. }
$$

Finally, as the availability time of the AGVs is evaluated as $95 \%$ of 2 shifts of 7 hours each, then

$$
\text { Tup }=13.3 \text { ( } \pi \text { hour). }
$$

and the throughput required by the picking system is

$$
T h=\bar{\lambda}=\frac{\text { miss }_{f p}}{\text { Tup }}=26.05\left(\frac{\text { missions }}{\text { hour }}\right) .
$$

6.2. Results. We then apply each of the various models of queues using the same system input parameters.

6.2.1. $\mathrm{M} / \mathrm{M} / \mathrm{s}$. In this model, the user population is infinite and without limit (unless otherwise stated), as is the queue (assumed infinite unless otherwise stated). The arrival rate to the system can be described as $\lambda$ of a single AGV multiplied by the number $U$ of active AGVs, while the service rate of the system is $\mu$ of each single picker multiplied by the number of pickers (supposing they can work in parallel on a single pallet).

The model description suggests that the number of pallets queued at the picking bay could reach infinity in the steady state. The queue is thus unable to self-regulate.

To satisfy the steady-state condition, it is necessary that $\rho \leq 1$.

In this model, $\rho$ is calculated as follows: 


$$
\rho=\frac{U \cdot \lambda}{s \cdot \mu} \leq 1 .
$$

If the arrival rate $(U \cdot \lambda)$ exceeds the service rate $(s \cdot \mu)$, the queue would tend to infinity, and the result would not be acceptable.

This model prevents the realization of a dimensioning in which the AGV must wait for the picker and not vice versa, excessively increasing $U$ to allow the pickers a utilization rate close to $100 \%$ would be impossible.

The outputs of this queue are given in Table 10 .

In addition to the fact that it is not possible to overcome a certain throughput of the system without increasing the number of pickers, a circular reference is hidden in the problem; by increasing the queue time, the rate of arrival at the picking bay should be reduced, but the arrival rate is used to determine the queue time. Thus, this system cannot be used for our purpose.

6.2.2. $M / M / s / K$. The $M / M / s / k$ queue adds a block at the maximum capacity of the queue, enabling this model to go beyond the limit of the $M / M / s$ queue because it is able to self-adjust.

$$
\lambda_{i}= \begin{cases}U \cdot \lambda, & \text { if } i<k, \\ 0, & \text { if } \geq k .\end{cases}
$$

Unfortunately, the circular reference between the duration of the queue and the rate of arrivals also prevents its use.

6.2.3. $M / M / s / . / U$. Of the standard models, this queue comes closest to describing the typical operation of a service system in which the number of users (in our case AGVs) present in the system over a certain time influences the number of potential customers remaining outside the system, and therefore, the average arrival rate is $\bar{\lambda}$. This is due to the finite population $U$ of AGVs.

The system is thus able to self-regulate in terms of traffic intensity $\rho$ and arrival rate $\bar{\lambda}$ without having to deal with circular references, as the rate of arrival $\lambda_{i}$ changes according to the state $i$ of system:

$$
\lambda_{i}=(U-i) \cdot \lambda \text {. }
$$

Despite this major advantage over the previous models, this model only fully represents a system characterised by Pallet_std, in which the system capacity $k$ corresponds exactly to the number of AGVs, i.e., $U$, as each AGV will always follow its pallet and will be waiting for the queue time plus the picking time on the pallet. This condition is very pessimistic and tends to overestimate the number of AGVs needed in the warehouse.

Table 11 provides the model outputs according to the various scenarios. The variables $T$ pallet and $T^{q}$ pallet are expressed in seconds.

Note that with standard inputs, at least 4 AGVs are needed to guarantee the necessary throughput of 26.05 missions per hour (Table $11,2^{\text {nd }}$ and $4^{\text {th }}$ rows).
From another analytical perspective, we could establish how many AGVs would be needed by worsening the input values, which are updated according to the maximum peak condition for the stock and picking missions of the case study (Table 6), that is,

$$
\begin{gathered}
\lambda=9.11\left[\frac{\text { missions }}{\text { hour } \times \mathrm{AGV}}\right], \\
\text { Th }=31.92\left[\frac{\text { missions }}{\text { hour }}\right] .
\end{gathered}
$$

Note that when modifying \#pick and \#stock, both Ttot and $T w h 1$ are updated.

Using these input parameters, we can conduct a multiscenario analysis to determine the number of AGVs. Note (Table $11,6^{\text {th }}-11^{\text {th }}$ rows) that 4 AGVs are not sufficient for the new throughput. The acceptable condition when maximising the use of pickers and subsequently minimising the number of AGVs is 5 AGVs and 1 picker.

Instead, by decreasing the service rate of the pickers as follows,

$$
\mu=40.00\left[\frac{\text { missions }}{\text { hour } \times \text { picker }}\right],
$$

the scenario that covers $95 \%$ of missions for each type (Table $11,12^{\text {th }}$ row) is well-served by 4 AGVs and 1 picker, but the handling potential of the AGVs falls to $71.01 \%$ (from $76.81 \%$ in the $2^{\text {nd }}$ row) due to the increase in service time and the consequent increase in queuing time (67.64 compared to 44.12 seconds in the normal case). The use of the pickers and the hours required for the system to complete the missions will also increase.

Even if we use the service rate of 40 (missions/hour), the configuration with 5 AGVs and 1 picker (Table $11,7^{\text {th }}$ row) is no longer valid, so to calculate an acceptable configuration that could cover the maximum value of the recorded cases, a configuration with $6 \mathrm{AGVs}$ and 1 very busy picker is necessary (Table $11,14^{\text {th }}$ row), but the queuing time increases to almost 150 seconds, thus revealing considerable congestion. Otherwise, we can limit the fleet to 5 AGVs using 2 pickers with half loads (Table 11, $15^{\text {th }}$ row).

6.2.4. $M / M / s / k / U$. The queue we propose and validate in this study is designed to best represent the specific system.

This has two main advantages over a simple $M / M / s / \cdot / U$ :

It is able to represent the dual nature of the pallets arriving at the picking station, Pallet_std and Pallet_end (Figures 1 and 2)

It allows AGVs to be independent from pallets and service time, as they can also complete a combined picking mission by returning a pallet back to the warehouse that has already been served by the picker and is different to that laid in the picking bay

Table 12 provides the outputs of the $M / M / s / k / U$ queue. Tpallet shows the expected waiting time for the pallet (the 
TABLE 11: Outputs of $M / M / s / \cdot / U$.

\begin{tabular}{|c|c|c|c|c|c|c|c|c|c|c|c|c|c|c|}
\hline Id & $\lambda$ & $\mu$ & $\mathbf{U}$ & $\mathbf{s}$ & $\lambda \cdot \mathbf{U}$ & $\bar{\lambda}$ & $\bar{\lambda} / \lambda \cdot U$ & Th & $\bar{\lambda} \geq \mathrm{Th} ?$ & $\rho(\%)$ & Npallet & Tpallet (sec) & $\mathrm{N}^{\mathrm{q}}$ pallet & $\mathrm{T}^{\mathrm{q}}$ pallet (sec) \\
\hline 1 & 9.32 & 49.69 & 3 & 1 & 27.97 & 22.29 & $79.70 \%$ & 26.05 & NO & 44.87 & 0.61 & 98.32 & 0.16 & 25.87 \\
\hline 2 & 9.32 & 49.69 & 4 & 1 & 37.30 & 28.65 & $76.81 \%$ & 26.05 & $\mathrm{OK}$ & 57.65 & 0.93 & 116.57 & 0.35 & 44.12 \\
\hline 3 & 9.32 & 49.69 & 3 & 2 & 27.97 & 23.51 & $84.03 \%$ & 26.05 & $\mathrm{NO}$ & 23.65 & 0.48 & 73.36 & 0.01 & 0.90 \\
\hline 4 & 9.32 & 49.69 & 4 & 2 & 37.30 & 31.22 & $83.71 \%$ & 26.05 & $\mathrm{OK}$ & 31.41 & 0.65 & 75.16 & 0.02 & 2.71 \\
\hline 5 & 9.32 & 49.69 & 3 & 3 & 27.97 & 23.55 & $84.20 \%$ & 26.05 & $\mathrm{NO}$ & 15.80 & 0.47 & 72.45 & 0.00 & 0.00 \\
\hline 6 & 9.11 & 49.69 & 4 & 1 & 36.42 & 28.19 & $77.38 \%$ & 31.92 & $\mathrm{NO}$ & 56.72 & 0.90 & 115.54 & 0.34 & 43.09 \\
\hline 7 & 9.11 & 49.69 & 5 & 1 & 45.53 & 33.75 & $74.13 \%$ & 31.92 & OK & 67.92 & 1.29 & 138.00 & 0.61 & 65.54 \\
\hline 8 & 9.11 & 49.69 & 4 & 2 & 36.42 & 30.61 & $84.05 \%$ & 31.92 & $\mathrm{NO}$ & 30.80 & 0.64 & 75.05 & 0.02 & 2.60 \\
\hline 9 & 9.11 & 49.69 & 5 & 2 & 45.53 & 38.05 & $83.58 \%$ & 31.92 & OK & 38.29 & 0.82 & 77.69 & 0.06 & 5.24 \\
\hline 10 & 9.11 & 49.69 & 4 & 3 & 36.42 & 30.78 & $84.50 \%$ & 31.92 & $\mathrm{NO}$ & 20.65 & 0.62 & 72.54 & 0.00 & 0.09 \\
\hline 11 & 9.11 & 49.69 & 5 & 3 & 45.53 & 38.45 & $84.45 \%$ & 31.92 & OK & 25.79 & 0.78 & 72.79 & 0.00 & 0.34 \\
\hline 12 & 9.32 & 40.00 & 4 & 1 & 37.30 & 26.48 & $71.01 \%$ & 26.05 & OK & 66.21 & 1.16 & 157.64 & 0.50 & 67.64 \\
\hline 13 & 9.11 & 40.00 & 5 & 1 & 45.53 & 30.65 & $67.32 \%$ & 31.92 & $\mathrm{NO}$ & 76.62 & 1.63 & 191.92 & 0.87 & 101.92 \\
\hline 14 & 9.11 & 40.00 & 6 & 1 & 54.63 & 34.15 & $62.52 \%$ & 31.92 & OK & 85.39 & 2.25 & 237.06 & 1.40 & 147.06 \\
\hline 15 & 9.11 & 40.00 & 5 & 2 & 45.53 & 36.39 & $79.92 \%$ & 31.92 & OK & 45.48 & 1.00 & 99.32 & 0.09 & 9.32 \\
\hline
\end{tabular}

TABle 12: Output of $M / M / s / k / U$.

\begin{tabular}{|c|c|c|c|c|c|c|c|c|c|c|c|c|c|c|c|c|c|c|}
\hline Id & $\lambda$ & $\mu$ & $U$ & $s$ & $k$ & $\lambda \cdot U$ & $\bar{\lambda}$ & $\bar{\lambda} / \lambda \cdot U$ & Th & $\bar{\lambda}>\mathrm{Th}$ & $p$ & Npallet & $T$ pallet & Nqpallet & Tqpallet & $N^{q} a g v$ & $T^{q} a g v$ & Savings \\
\hline 1 & 9.32 & 49.69 & 3 & 1 & 3 & 27.97 & 23.24 & $83.09 \%$ & 26.05 & $\mathrm{NO}$ & $46.78 \%$ & 0.68 & 105.69 & 1 & 33 & 0.51 & 78.57 & $25.66 \%$ \\
\hline 2 & 9.32 & 49.69 & 3 & 1 & 4 & 27.97 & 25.83 & $92.34 \%$ & 26.05 & $\mathrm{NO}$ & $51.98 \%$ & 90 & 24 & & 88 & 23 & 04 & $42 \%$ \\
\hline 3 & 9.32 & 49.69 & 3 & 1 & 5 & 27.97 & 26.95 & $96.34 \%$ & 26.05 & OK & $54.23 \%$ & 1.05 & 139.84 & 50 & 67.39 & 11 & 68 & $9.50 \%$ \\
\hline 4 & 9.32 & 49.69 & 3 & 2 & 3 & 27.97 & 24.48 & $87.51 \%$ & 26.05 & $\mathrm{NO}$ & $24.63 \%$ & 0.50 & 74.13 & 0.01 & 1.68 & 0.37 & 55.10 & $25.67 \%$ \\
\hline 5 & 9.32 & 49.69 & 3 & 2 & 4 & 27.97 & 27.20 & $97.23 \%$ & 26.05 & OK & $27.37 \%$ & 0.58 & 76.21 & 0.03 & 3.76 & 0.08 & 10.99 & $85.58 \%$ \\
\hline 6 & 9.11 & 49.69 & 4 & 1 & 4 & 36.42 & 29.41 & $80.73 \%$ & 31.92 & NO & $59.18 \%$ & 1.04 & 126.74 & 0.44 & 54.28 & 0.77 & 35 & $25.56 \%$ \\
\hline 7 & 9.11 & 49.69 & 4 & 1 & 5 & 36.42 & 32.32 & $88.73 \%$ & 31.92 & OK & $65.04 \%$ & 1.37 & 152.82 & 2 & 80.36 & 5 & .23 & $67.13 \%$ \\
\hline 8 & 9.11 & 49.69 & 4 & 2 & 4 & 36.42 & 31.85 & $87.45 \%$ & 31.92 & $\mathrm{NO}$ & $32.05 \%$ & 0.68 & 76.33 & 0.03 & 3.88 & 0 & 56.74 & $25.66 \%$ \\
\hline 9 & 9.11 & 49.69 & 4 & 2 & 5 & 36.42 & 35.09 & $96.34 \%$ & 31.92 & OK & $35.31 \%$ & 0.77 & 33 & 0 & 6.87 & 0 & 15.01 & $81.08 \%$ \\
\hline 10 & 9.11 & 49.69 & 4 & 3 & 4 & 36.42 & 32.04 & $87.98 \%$ & 31.92 & OK & $21.50 \%$ & 0.65 & 72.68 & 0.00 & 0.23 & 0.48 & 54.02 & $25.67 \%$ \\
\hline 11 & 9.32 & 40.00 & 3 & 1 & 5 & 27.97 & 26.02 & $93.02 \%$ & 26.05 & $\mathrm{NO}$ & $65.05 \%$ & 1.46 & 202.24 & 0.81 & 112.24 & 0.21 & 28.98 & $85.67 \%$ \\
\hline 12 & 9.32 & 40.00 & 3 & 1 & 6 & 27.97 & 26.77 & $95.72 \%$ & 26.05 & OK & $66.93 \%$ & 1.68 & 225.47 & 1.01 & 135.47 & 0.13 & 17.27 & $92.34 \%$ \\
\hline 13 & 9.32 & 40.00 & 4 & 1 & 4 & 37.30 & 27.76 & $74.43 \%$ & 26.05 & OK & $69.39 \%$ & 1.37 & 177.96 & 0.68 & 87.96 & 1.02 & 132.67 & $25.45 \%$ \\
\hline 14 & 9.11 & 40.00 & 4 & 1 & 5 & 36.42 & 30.11 & $82.67 \%$ & 31.92 & $\mathrm{NO}$ & $75.27 \%$ & 1.8 & 220.09 & 1. & 130.09 & 0.69 & 82.89 & $62.34 \%$ \\
\hline 15 & 9.11 & 40.00 & 4 & 1 & 6 & 36.42 & 31.71 & $87.07 \%$ & 31.92 & $\mathrm{NO}$ & $79.29 \%$ & 2.34 & 265.09 & 1.54 & 175.09 & 0.52 & 58.69 & $77.86 \%$ \\
\hline 16 & 9.11 & 40.00 & 4 & 1 & 7 & 36.42 & 32.76 & $89.94 \%$ & 31.92 & OK & $81.90 \%$ & 2.81 & 309.03 & 1.99 & 219.03 & 0.40 & 44.22 & $85.69 \%$ \\
\hline 17 & 9.11 & 40.00 & 5 & 1 & 5 & 45.53 & 32.03 & $70.34 \%$ & 31.92 & OK & $80.06 \%$ & 1.99 & 223.72 & 1.19 & 133.72 & 1.48 & 166.68 & $25.50 \%$ \\
\hline 18 & 9.11 & 40.00 & 4 & 2 & 5 & 36.42 & 34.38 & $94.41 \%$ & 31.92 & OK & $42.98 \%$ & 0.98 & 102.59 & 0.12 & 12.59 & 0.22 & 23.43 & $77.17 \%$ \\
\hline
\end{tabular}

waiting time for the $\mathrm{AGV}$ in the previous system $\mathrm{M} / \mathrm{M} / \mathrm{s} / \cdot \mathrm{U})$. Saving represents the savings achieved by using $T_{a g v}^{q}$ calculated by means of this model.

Compared to the previous queue, we have an additional parameter to modify (i.e., $k$ ), which enables us to achieve the goal $(\bar{\lambda} \geq T h)$ with minimal effort.

The combined action of the parameters $s$ and $k$ enables us to increase the effective throughput of the system (i.e., $\bar{\lambda}$ ) and to achieve up to $97.23 \%$ of the potential of movement offered by the AGV fleet (i.e., $\lambda \cdot U$ ) when 3 AGVs, 2 pickers, and 4 pallet places are available in the picking bay (Table 12, $5^{\text {th }}$ row).

This queue allows us to check many details of the system in the design. Clearly, only $3 \mathrm{AGV}$ s are needed to guarantee the throughput of 26.05 missions per hour, but the details of having 1 picker with 5 pallet places (Table $12,3^{\text {rd }}$ row) or 2 pickers and 4 pallet places (Table $12,5^{\text {th }}$ row) are added and are important because they involve considerable warehouse management costs.
In addition, the service rate $\mu$ must be checked, as it is crucial for the queue dynamics. A lower service rate would require an increase in the number of pallet places in the picking bay, but this is not always possible because the space in the picking bay is generally limited and the equipment in it is expensive. Thus, if it was not possible to arrive at $k=6$ (Table $12,12^{\text {th }}$ row), then it would be necessary to increase the number of AGVs by raising the initial investment.

We can then analyse how many AGVs would be necessary to guarantee a throughput that includes the peaks of the picking missions and the storage missions. In this case, 4 AGVs and 1 picker would only be needed (recall that in the previous queue, the minimum number of $\mathrm{AGVs}$ to cover the peak is 5) by simply increasing the number of pallet places in the picking bay to 5 .

If instead the picker worked at a slower rate, it would be sufficient to increase the capacity of the system $k$ to up to 7 to guarantee an effective throughput equal to 32.76 picking missions every hour, without increasing the number of 
AGVs. Note that even with $k=6$, a satisfactory level of throughput would be reached, although it does not meet the required level.

Recall that with the queue $M / M / s / \cdot / U$, at least 6 AGVs are needed to cover the peak with only 1 slower picker. This major difference $(+50 \%$ of the requested AGVs) demonstrates the value of the new model of queue presented here, which has been created to solve a sizing problem for a picking station under real setting conditions.

\section{Conclusions and Further Research Agenda}

In this study, we address the problem of picking in a finished product warehouse and propose an innovative model of the queue $M / M / s / k / U$, where two types of pallets are taken into account, i.e., Pallet_std, which must be returned to the warehouse after the service, and Pallet_end, which is destined to end after the operator picks it up and then releases the AGV as soon as it is placed in the picking bay.

This innovative queue model is first validated through the use of a discrete-event simulator $\left(\right.$ AnyLogic $\left.^{\circledR}\right)$ and is then tested on real data and compared with other standard queue models. The analytical model here proposed aims to size the picking system in terms of the number of pickers, the size of the picking bay, and the size of the AGV fleet, as these interrelated control variables were never designed jointly. This represents the main stretch of our model from a managerial viewpoint, as it allows to design the picking area in terms of the said variables without recurring to mathematical programming and complex solving strategies for nonlinear models. Furthermore, the multiscenario analysis used to design the picking area provides to the designer as many outputs, clarifies the behaviour of the system when changing the decision variables, and thus drives the decision-makers towards more rational choices. Finally, it can be observed that different solutions can be implemented when varying the inputs, in particular the intensity of customer orders to fulfil.

In further research, the system could be represented as a network of three queues, among which the picking bay shows a block, i.e., limited capacity, and the others with infinite capacity of type $M / G / U_{x}(t)$, with the sum of AGVs for each of the possible states of the system limited to $U$. Thus, the service system would be an $M / M / s / k / U$ queue, with $s$ pickers always available, while the other two queues would be characterised by $U_{x}(t)$ operators with $\sum_{x=1}^{3} U_{x}(t)=U$ for each time instant $t$.

A different logic capable of reducing AGV waiting time to almost zero would also minimise the amount of empty trips and maximise the throughput at the picking station, and thus it is worthy of assessment.

A final limitation of our work concerns the availability of AGVs, which due to the lack of data was calculated for 95\% of the total time available. The probabilities that in the steady state there would be $j$ AGVs operating, with $j=0,1, \ldots U$, could instead be calculated through carefully examining the fault behaviour and modifying the offered movement potentiality (i.e., $j \lambda$ ) by changing $\lambda_{i}$ expected in a given instant $t$.

\section{Data Availability}

The data used to validate the model are derived from a real case study and are included within the article.

\section{Conflicts of Interest}

The authors declare that they have no conflicts of interest.

\section{References}

[1] J. A. Tompkins, J. A. White, Y. A. Bozer, and J. M. A. Tanchoco, "Facilities planning," Wiley, 2003.

[2] B. Rouwenhorst, B. Reuter, V. Stockrahm, G. J. Van Houtum, R. J. Mantel, and W. H. M. Zijm, "Warehouse design and control: framework and literature review," European Journal of Operational Research, vol. 122, no. 3, pp. 515-533, 2000.

[3] R. N. Anthony, Planning and Control Systems: A Framework for Analysis, H. U. Boston, Division of Research, Graduate School of Business Administration, Greater Noida, India, 1965.

[4] H. Davarzani and A. Norrman, "Toward a relevant agenda for warehousing research: literature review and practitioners' input," Logistics Research, vol. 8, no. 1, 2015.

[5] T. van Gils, K. Ramaekers, A. Caris, and R. B. M. de Koster, "Designing efficient order picking systems by combining planning problems: state-of-the-art classification and review," European Journal of Operational Research, vol. 267, no. 1, pp. 1-15, 2018.

[6] J. P. Van den Berg, "A literature survey on planning and control of warehousing systems," IIE Transactions, vol. 31, no. 8, pp. 751-762, 1999.

[7] J. Gu, M. Goetschalckx, and L. F. McGinnis, "Research on warehouse operation: a comprehensive review," European Journal of Operational Research, vol. 177, no. 1, pp. 1-21, 2007.

[8] F. Lolli, R. Gamberini, C. Giberti, B. Rimini, and F. Bondi, "A simulative approach for evaluating alternative feeding scenarios in a kanban system," International Journal of Production Research, vol. 54, no. 14, pp. 4228-4239, 2016.

[9] E. KearneY, Excellence in Logistics 2004, 2004.

[10] R. de Koster, T. Le-Duc, and K. J. Roodbergen, "Design and control of warehouse order picking: a literature review," European Journal of Operational Research, vol. 182, no. 2, 2007a.

[11] R. de Koster, T. Le-Duc, and K. J. Roodbergen, "Design and control of warehouse order picking: a literature review," European Journal of Operational Research, vol. 182, no. 2, pp. 481-501, 2007b.

[12] F. Dallari, G. Marchet, and M. Melacini, "Design of order picking system," International Journal of Advanced Manufacturing Technology, vol. 42, no. 1-2, pp. 1-12, 2009.

[13] J. O. Matson and J. A. White, "Operational research and material handling," European Journal of Operational Research, vol. 11, no. 4, pp. 309-318, 1982.

[14] C. S. Yoon and G. P. Sharp, "A structured procedure for analysis and design of order pick systems," IIE Transactions, vol. 28, no. 5, pp. 379-389, 1996.

[15] M. J. Rosenblatt and Y. Roll, "Warehouse capacity in a stochastic environment," International Journal of Production Research, vol. 26, no. 12, pp. 1847-1851, 1988. 
[16] S. S. Heragu, L. Du, R. J. Mantel, and P. C. Schuur, "Mathematical model for warehouse design and product allocation," International Journal of Production Research, vol. 43, no. 2, pp. 327-338, 2005.

[17] Y. Jaghbeer, R. Hanson, and M. I. Johansson, "Automated order picking systems and the links between design and performance: a systematic literature review," International Journal of Production Research, vol. 58, no. 15, pp. 4489-4505, 2020.

[18] T. Le-Anh and M. B. M. De Koster, "A review of design and control of automated guided vehicle systems," European Journal of Operational Research, vol. 171, no. 1, pp. 1-23, 2006.

[19] J. R. Van der Meer, "Operational control of internal transport," Series Research in Management, vol. 1, 2000.

[20] F. F. Choobineh, A. Asef-Vaziri, and X. Huang, "Fleet sizing of automated guided vehicles: a linear programming approach based on closed queuing networks," International Journal of Production Research, vol. 50, no. 12, pp. 3222-3235, 2012.

[21] P. J. Egbelu and J. M. A. Tanchoco, "Characterization of automatic guided vehicle dispatching rules," International Journal of Production Research, vol. 22, no. 3, pp. 359-374, 1984.

[22] D. Newton, "Simulation model helps determine how many automatic guided vehicles that are needed," International Journal of Production ResearchInternational Journal of Production Research, vol. 23, no. 2, pp. 68-79, 1985.

[23] A. Asef-Vaziri, B. Khoshnevis, and M. Rahimi, "Design and analysis of an automated container handling system in seaports," International Journal of Agile Systems and Management, vol. 3, no. 1-2, pp. 112-126, 2008.

[24] P. Egbelu, "The use of non-simulation approaches in estimating vehicle requirements in an automated guided vehicle based transport system," Material Flow, vol. 4, no. 1, pp. 17-32, 1987.

[25] J. A. Muckstadt, "Design of automatic guided vehicle systems," AIIE Transactions, vol. 14, no. 2, pp. 114-124, 1982.

[26] B. Mahadevan and T. T. Narendran, "Estimation of number of AGVs for an FMS: an analytical model," International Journal of Production Research, vol. 31, no. 7, pp. 1655-1670, 1993.

[27] R. Arifin and P. J. Egbelu, "Determination of vehicle requirements in automated guided vehicle systems: a statistical approach," Production Planning \& Control: Management and operations, vol. 11, no. 3, pp. 258-270, 2013.

[28] M. Dell'Amico, M. Fischetti, and P. Toth, "Heuristic algorithms for the multiple depot vehicle scheduling problem," Management Science, vol. 39, no. 1, pp. 115-125, 1993.

[29] S. Rajotia, K. Shanker, and J. L. Batra, "Determination of optimal AGV fleet size for an FMS," International Journal of Production Research, vol. 36, no. 5, pp. 1177-1198, 1998.

[30] I. F. A. Vis, R. De Koster, K. J. Roodbergen, and L. W. P. Peeters, "Determination of the number of automated guided vehicles required at a semi-automated container terminal," Journal of the Operational Research Society, vol. 52, no. 4, pp. 409-417, 2001.

[31] J. Yoda, "Determination of the total number of ions confined in an rf ion trap," Japanese Journal of Applied Physics, vol. 26, no. 8R, pp. 1390-1391, 1987.

[32] R. A. Wysk, P. J. Egbelu, C. Zhou, and B. K. Ghosh, "Use of spread sheet analysis for evaluating AGV systems," Material Flow, vol. 4, no. 1-2, pp. 53-64, 1987.

[33] L. Talbot, Design and Performance Analysis of Multistation Automated Guided Vehicle Systems, Universite Catholique de Louvain, Ottignies-Louvain-la-Neuve, Belgium, 2003. 